\title{
POLÍTICA SOCIAL NO BRASIL prioridades erradas, incentivos perversos
}

José Márcio Camargo

\begin{abstract}
Resumo: Este artigo mostra que os programas sociais brasileiros têm um viés pró-idoso e outro anticriança, o que os torna pouco eficientes no sentido de diminuir a desigualdade da renda e a pobreza no país. O resultado desta estrutura de gastos sociais criou um mecanismo de reprodução da pobreza ao longo do tempo.

Palavras-chave: políticas sociais; pobreza; incentivos e crescimento.

Abstract: This article shows that the Brazilian social programs have a tendency pro-elderly and another anti-children, that makes them less efficient in order to reduce the inequality of income and the poverty in the country. The result of such structure of social expenditures has created a mechanism of reproduction of poverty along the years.

Key words: social politics; poverty; incentives and growth.
\end{abstract}

$\sim$ omo deve ser estruturada a política social de um país? A resposta a esta pergunta independe do grau de desenvolvimento da nação, da porcentagem de pobres existentes, do nível de desigualdade na distribuição da renda e da estrutura etária da população? Qual o papel dos gastos sociais do Estado na redução da desigualdade e da pobreza? As respostas não são únicas e estão na raiz do debate sobre a forma como devem ser estruturados os programas sociais no Brasil e em outros países.

Em primeiro lugar, as respostas a estas perguntas dependem da definição dos objetivos que os programas sociais pretendem alcançar. Em outras palavras, por que um Estado decide taxar seus cidadãos e utilizar os recursos assim obtidos para desenvolver programas nas áreas de saúde, educação, previdência social, assistência social e trabalho? Existem diferentes respostas para esta pergunta.

Uma delas seria considerar o objetivo dos programas sociais a redução das desigualdades na distribuição da renda e nos níveis de pobreza, decorrentes de falhas no funcionamento dos mercados. Ou seja, se, devido a externalidades positivas ou negativas, assimetria de informações, mercado de crédito imperfeito, etc., o resultado do funcionamento do mercado gera uma distribuição da renda e níveis de pobreza indesejáveis para a sociedade, as políticas sociais poderiam ser utilizadas para contrabalançar estes resultados.

Uma resposta alternativa seria que os programas sociais têm por objetivo criar uma rede de proteção social para todos os cidadãos do país, fazendo com que, diante de imprevistos como desemprego, acidentes no trabalho, doença, etc., ou em face de situações previsíveis, mas que os cidadãos, por alguma razão, não conseguiram antecipar adequadamente, como a perda da capacidade de trabalho devido à idade avançada, pouco investimento em capital humano, etc., consigam manter um padrão de vida mínimo adequado à sua sobrevivência.

Uma terceira possibilidade seria considerar objetivo dos programas a manutenção do padrão de vida de todos os cidadãos, diante de situações imprevistas ou previsíveis mas não devidamente antecipadas, em um nível o mais próximo possível daquele vigente antes que tais situações se manifestassem.

Todas estas são respostas possíveis e não excludentes entre si. Desta forma, a estrutura da política social será dada por uma combinação destas respostas, adotando-se diferentes ênfases em determinados momentos do tempo e em condições sociais divergentes. 
A escolha entre estas alternativas (que, por sinal, não esgotam as possibilidades disponíveis) depende de vários fatores, entre os quais destacam-se três:

- volume de recursos;

- definição de prioridades, o que depende das condições e dos indicadores sociais vigentes em cada país e em cada momento;

- geração de incentivos.

O objetivo deste artigo é, a partir da análise das diferentes respostas que podem ser dadas a estas perguntas, avaliar a estrutura da política social brasileira com base na estrutura de gastos sociais do governo.

\section{RECURSOS, PRIORIDADES E INCENTIVOS}

O volume de recursos disponível para a implementação dos programas sociais define os limites de atuação do Estado. À medida que se passa da primeira para a terceira alternativa, amplia-se o grau de abrangência dos programas e, como resultado, o volume de recursos necessário aumenta rapidamente. Por exemplo, se o sistema educacional público deve ter como objetivo o atendimento gratuito de todos os cidadãos em todos os níveis de ensino, os gastos serão muito maiores do que se estiver concentrado apenas no ensino fundamental.

Como os recursos são escassos, a definição do grau de abrangência dos programas sociais está diretamente relacionada à definição de prioridades por parte do Estado. Dado o volume de recursos, quanto mais universal for o sistema, menor, em termos relativos, a parcela de recursos destinada aos grupos mais pobres da população. No limite (terceira alternativa), a distribuição dos recursos dos programas sociais estaria apenas replicando e validando a distribuição da renda gerada pelo funcionamento do mercado (na verdade, esta proposição não é totalmente verdadeira, pois o resultado de mercado não é independente da estrutura dos programas sociais, como veremos a seguir).

Da mesma forma, dado o volume de recursos, quanto mais abrangentes forem os programas, menor a parte dos mesmos que pode ser destinada a cada programa individualmente. Como resultado, o ajuste acaba ocorrendo na qualidade do serviço prestado à população. Como os grupos de renda mais elevada, ao contrário daqueles de renda mais baixa, têm a opção de pagar pela prestação dos serviços no setor privado, a queda de qualidade acaba sendo uma forma perversa de focalizar os programas sociais para os pobres.
Portanto, a relação entre volume de recursos disponíveis e abrangência dos programas sociais é de fundamental importância. Quanto maior esta relação, maior é a probabilidade de que os ajustes ocorram através da redução da qualidade dos serviços prestados à população, o que gera uma forma perversa de focalização para os membros mais pobres da sociedade. Neste caso, não apenas o objetivo de abrangência deixa de ser alcançado, pois os ricos acabam deslocando suas demandas para o setor privado, mas também os mais pobres têm um atendimento de baixa qualidade. Em outras palavras, quanto menor a relação entre disponibilidade de recursos e abrangência dos programas, menor a probabilidade de que os objetivos dos mesmos sejam devidamente atingidos.

$\mathrm{O}$ terceiro aspecto destacado anteriormente trata dos incentivos gerados pelos programas sociais. Existem diferentes incentivos, dependendo da estrutura destes programas, que precisam ser considerados para evitar distorções que acabam tornando os programas menos efetivos e gerando ineficiências na alocação de recursos. Um exemplo bastante estudado na literatura são os incentivos criados por um sistema de seguro-desemprego excessivamente benevolente. Se um trabalhador, ao ficar desempregado, recebe um benefício cujo valor é próximo de seu salário por um período muito prolongado de tempo, cria-se um incentivo para que este trabalhador reduza a intensidade de busca de um novo emprego. Como resultado, a taxa de desemprego tende a aumentar.

Qualquer programa social gera incentivos. Ao prover assistência universal e gratuita à saúde, o programa estará gerando um incentivo para que as pessoas utilizem mais o sistema. A questão é como desenhar os programas de tal forma a gerar os incentivos corretos, para que sejam sustentáveis do ponto de vista fiscal, induzam a comportamentos considerados adequados pela sociedade e não provoquem ineficiência na alocação de recursos. Portanto, a preocupação com o desenho dos programas é tão importante quanto a sua própria existência.

\section{GASTOS SOCIAIS NO BRASIL - O VIÉS PRÓ-IDOSOE ANTICRIANÇA}

O governo federal brasileiro gasta, anualmente, mais de R \$ 200 bilhões com programas sociais, aí incluídos educação, saúde, previdência social, assistência social e trabalho. Este total de gastos sociais é relativamente elevado ao se comparar com a necessidade de recursos para eliminar totalmente a pobreza no país. Apenas a título de ilus- 
tração, se fosse possível identificar exatamente quem são as pessoas que vivem em situação de extrema pobreza no país e desenhar um programa de transferência de rendas diretamente a estas pessoas, o total de recursos necessário para tirá-las da situação de extrema pobreza corresponderia a não mais que $4 \%$ do total de gastos sociais.

Partindo da suposição de que dois dos objetivos dos programas sociais brasileiros são diminuir a proporção da população que vive abaixo da linha de pobreza e reduzir a desigualdade da distribuição da renda, a relativa constância destas duas variáveis, ao longo das últimas décadas (Gráfico 1) (Barros; Henriques; Mendonça, 2000a), deve-se à estrutura da distribuição destes gastos entre os diferentes grupos sociais e as diversas áreas nas quais eles são alocados. O ponto é que um real gasto em um programa social pode ser apropriado por uma família pobre ou por uma família não pobre. Entretanto, um real gasto com seguro-desemprego tem efeitos totalmente diferentes, sobre a pobreza presente e a futura, daquele mesmo real gasto na educação das crianças das famílias pobres.

Desta forma, a qualidade de um determinado programa social, no sentido de atingir os objetivos propostos pela sociedade, depende:

- da escolha correta da clientela à qual está direcionado o programa;

\section{GRÁFICO 1}

Incidência da Pobreza e da Indigência Brasil - 1977-1997

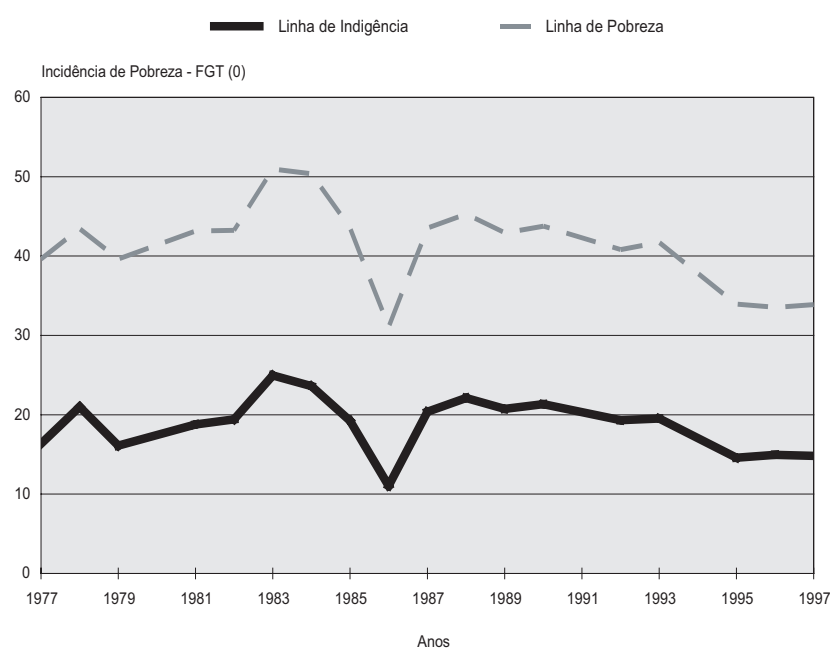

Fonte: Barros; Henriques; Mendonça, 2000a. Baseado nas pesquisas da PNAD, 1977-1997.
- de o desenho do programa garantir que os recursos sejam efetivamente apropriados por esta clientela;

- de o desenho do programa estar de acordo com as necessidades desta clientela, gerando os incentivos corretos, ou seja, induzindo as pessoas a se comportarem de tal forma que os objetivos sejam atingidos.

A pergunta é: por que o gasto social brasileiro tem sido tão ineficiente para reduzir a pobreza e a desigualdade da distribuição da renda ao longo do tempo? Será que o problema está no fato de a clientela à qual os programas são dirigidos não ser correta para atingir este objetivo, ou o desenho dos programas é tal que os recursos não são efetivamente apropriados pela clientela-alvo, ou os incentivos gerados não são compatíveis com os objetivos?

O principal gasto social do governo brasileiro é a previdência social (Ministério da Fazenda, 2003), que recebe R $\$ 125$ bilhões do total. Isto significa que mais de $60 \%$ dos gastos sociais do governo federal brasileiro se destinam a financiar aposentadorias e pensões, em um país que tem 5,85\% de sua população com 65 anos ou mais. Este padrão está totalmente fora da norma internacional. Países como Coréia do Sul, México e Turquia, que têm porcentagem de idosos similares à do Brasil, gastam menos da metade com aposentadorias e pensões como proporção do PIB. Já países como Estados Unidos, Canadá, Austrália e Japão, com porcentagens de idosos acima de $15 \%$ da população, têm gastos próximos a $10 \%$ de seus respectivos PIB nesta área. Apenas os países do continente europeu, cuja porcentagem de idosos está acima de $20 \%$ da população, possuem gastos tão ou mais elevados como proporção do PIB quanto o Brasil (Pinheiro, 2004).

Sem dúvida, uma parte significativa deste total de gastos com aposentadorias e pensões é financiada pelas contribuições dos próprios beneficiários, o que caracterizaria a compra de um seguro e não um gasto social strictu senso. Entretanto, além de o país continuar gastando o dobro, como proporção do PIB, se comparado a países com porcentagem de idosos similar à brasileira, o que gera problemas importantes que serão analisados a seguir, o déficit do sistema, somente no âmbito do governo federal, chega a mais de $4 \%$ do PIB e tem uma tendência crescente, desde o início dos anos 90.

O viés pró-idoso dos gastos sociais no Brasil não se esgota na previdência social. Do total de R\$10 bilhões despendidos em assistência social, cerca de R $\$ 5$ bilhões, ou seja, a metade, são destinados aos idosos. Os gastos 
com assistência social de crianças e adolescentes correspondem a R \$ 3,5 bilhões.

Enquanto os gastos com a previdência e a assistência social ao idoso atingem $12 \%$ do PIB, as estimativas do Banco Mundial, para 2000, são de que o país gastava 5,5\% do PIB com educação (R $\$ 63$ bilhões). ${ }^{1}$ Deste total, 18\% (R\$ 11 bilhões) são de responsabilidade do governo federal, $44,5 \%$ (R $\$ 28$ bilhões) dos governos estaduais e 37,5\% (R $\$ 24$ bilhões) dos governos municipais.

Do total dos gastos do governo federal, 60\% (R\$ 6,6 bilhões) eram destinados ao financiamento do ensino superior, R \$ 800 milhões ao ensino médio e profissional e R\$ 1,3 bilhão para o ensino fundamental. Quanto aos outros níveis de governo, estima-se que, em 2000, os gastos dos Estados com ensino fundamental tenham atingido $\mathrm{R} \$ 15,4$ bilhões, enquanto $\mathrm{R} \$ 8,7$ bilhões foram destinados ao ensino médio. Já os municípios dedicaram R $\$ 24$ bilhões ao ensino fundamental. Portanto, no total, estima-se que os diferentes níveis de governo gastavam R\$ 10 bilhões com o ensino médio ( $0,8 \%$ do PIB) e aproximadamente $\mathrm{R} \$$ 42 bilhões (3,6\% do PIB) com o fundamental (Schwartzman, 2004).
Por outro lado, do total de gastos com assistência social em 2003 (R\$ 10,2 bilhões), cerca de R \$ 2,5 bilhões foram destinados às crianças, através dos programas bolsaescola, erradicação do trabalho infantil e programas de creches, principalmente.

Sendo a educação fundamental o principal gasto social destinado às crianças ( 0 a 14 anos de idade) e considerando-se que as crianças correspondiam a $29,6 \%$ da população do país em 2000, os dados mostram o enorme viés anticriança e pró-idoso dos gastos sociais brasileiros. Com apenas $5,85 \%$ de sua população com 65 anos ou mais $(9,9$ milhões de pessoas), o país gasta $12 \%$ do PIB com aposentadorias e pensões, enquanto os gastos com ensino fundamental, que atende a $29,6 \%$ da população do país (50,2 milhões de pessoas tinham, em 2000, entre 0 e 14 anos de idade), correspondem a 3,6\% do PIB.

Portanto, ao se considerar o critério de porcentagem de gastos, a política social brasileira escolheu como sua clientela os idosos. O resultado líquido pode ser observado no Gráfico 2.

Enquanto $50 \%$ das crianças pertencem a famílias pobres, apenas $10 \%$ dos idosos vivem em famílias com ren-

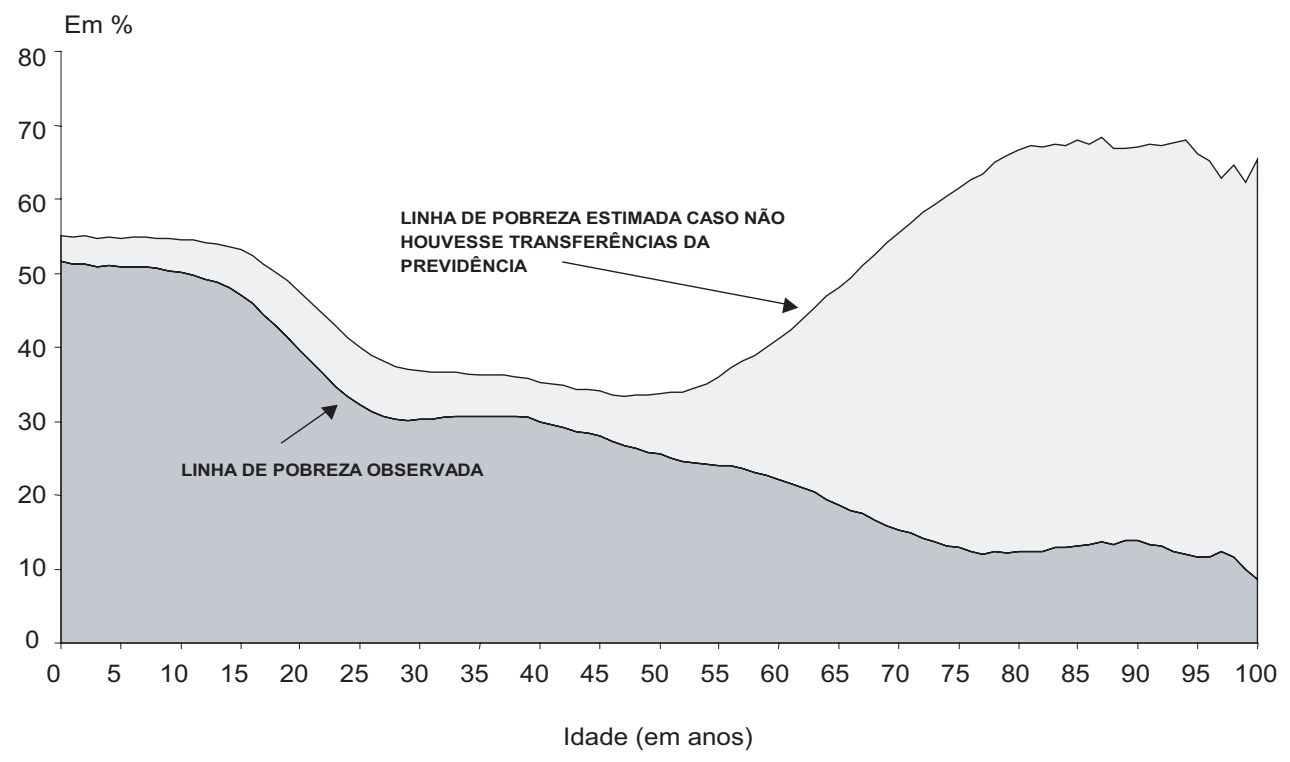


da per capita familiar menor que a linha de pobreza. $O$ efeito dos gastos da previdência social na redução da pobreza entre as pessoas com mais de 55 anos de idade é extremamente importante e aumenta com a idade. Caso não houvesse previdência social no Brasil, mais de $60 \%$ das pessoas com mais de 80 anos seriam pobres. Portanto, se o objetivo da política social brasileira é reduzir a pobreza entre os idosos, ela tem sido extremamente bem sucedida. O problema é que, ao concentrar os recursos no atendimento dos idosos, a política social brasileira abandonou as crianças, como bem mostra o Gráfico 2.

\section{ESTRUTURA DOS GASTOS SOCIAIS NO BRASIL - O VIÉS ANTIPOBRES}

Uma vez definida a principal clientela dos gastos sociais no Brasil, o segundo aspecto a ser considerado quanto à estrutura dos gastos sociais é quem se apropria dos mesmos. Em outras palavras, quais os grupos de renda que mais se beneficiam com estes gastos. Se um dos objetivos das políticas sociais é reduzir a desigualdade na distribuição da renda e a pobreza, estes programas deveriam se direcionar, prioritariamente, para os grupos de renda mais baixa. Entretanto, apesar de os gastos da previdência social no Brasil serem de grande importância para reduzir a pobreza entre os idosos, como visto anteriormente, em conjunto, o desenho dos programas sociais no país faz com que mais de $60 \%$ destes recursos sejam apropriados pelos $40 \%$ mais ricos da população.

A Tabela 1 mostra a distribuição dos gastos com aposentadorias e pensões e com o programa de seguro-desemprego, por quintil da distribuição da renda no Brasil. Como pode ser observado, do total de gastos com pensões e aposentadorias, $65 \%$ são apropriados pelos $20 \%$ mais ricos da

TABELA 1

Distribuição dos Gastos do Governo em Pensões e Seguro-Desemprego, segundo Faixas de Renda

Brasil - 1996

Em porcentagem

\begin{tabular}{lcc}
\hline Faixas de Renda & Pensões & Seguro-Desemprego \\
\hline Primeiro Quintil & 2,4 & 3,0 \\
Segundo Quintil & 6,4 & 21,0 \\
Terceiro Quintil & 9,7 & 20,2 \\
Quarto Quintil & 16,5 & 36,3 \\
Quinto Quintil & 65,1 & 19,5 \\
\hline
\end{tabular}

Fonte: Camargo; Ferreira, (2002). população e $81,6 \%$ pelos $40 \%$ mais ricos, enquanto os $40 \%$ mais pobres detêm $8,8 \%$ do total. Ao se comparar esta informação com aquela resultante do Gráfico 2, pode-se concluir que com $8,8 \%$ dos gastos destinados à previdência foi possível reduzir a porcentagem de pobres entre os idosos de mais de $60 \%$ para $10 \%$ do total. Da mesma forma, somente $24,0 \%$ dos gastos com seguro-desemprego vão para os $40 \%$ mais pobres, enquanto $50 \%$ são recebidos pelos $40 \%$ mais ricos.

Como mais de $60 \%$ dos gastos sociais do governo federal são alocados para o pagamento de aposentadorias e pensões e $65 \%$ deste total é apropriado pelos $20 \%$ mais ricos da população, 39\% dos gastos sociais do governo federal são destinados aos $20 \%$ mais ricos da população brasileira. Ao se considerar que os $20 \%$ seguintes detêm $16,5 \%$ dos gastos com aposentadoria, em conjunto, os $40 \%$ mais ricos recebem $50 \%$ dos gastos sociais do governo federal.

$\mathrm{Na}$ verdade, o sistema de aposentadorias no Brasil, em vez de reduzir, aumenta a desigualdade na distribuição da renda. Em artigo recente, Hoffmann (2003:135) calcula a contribuição do sistema de aposentadorias para o coeficiente de Gini no Brasil. Utilizando dados da PNAD 2002, o autor mostra que a razão de concentração dos rendimentos de aposentadorias e pensões é de 0,593, enquanto para os rendimentos do trabalho de empregados é de 0,544.

Para o conjunto de transferências do governo, a situação não é menos dramática. A Tabela 2 mostra o valor das transferências realizadas pelo governo federal, por decil da distribuição da renda no Brasil. Como pode-se observar, enquanto os $10 \%$ mais pobres recebem, em média, $\mathrm{R} \$ 391,00$ por ano em transferências governamentais, os $10 \%$ mais ricos recebem $\mathrm{R} \$ 8.177,00$. Note que, apesar de as aposentadorias representarem a maior parte do valor das transferências do governo federal, dos cinco programas de transferências do governo, apenas o de renda mínima, que inclui o bolsa-escola, bolsa-alimentação e bolsa-criança cidadã, e o de amparo ao idoso (Loas) atendem prioritariamente aos mais pobres. Os outros três programas de transferências - aposentadorias e pensões, seguro-desemprego e abono salarial e salário-família - atingem, principalmente, os grupos que estão no meio da distribuição da renda.

Este viés dos programas de transferência de renda, que favorece os $40 \%$ mais ricos da população do país, persiste, em parte, quando são analisados os gastos com educação. A Tabela 3 mostra quem tem acesso às escolas públicas, por faixa de renda. Como pode-se observar, na escola 
TABELA 2

Valor das Transferências do Governo Federal, por Decil da Distribuição da Renda

Brasil - 2002

Em reais

\begin{tabular}{|c|c|c|c|c|c|c|c|c|c|c|}
\hline \multirow{2}{*}{ Transferências } & \multicolumn{10}{|c|}{ Decis de Domicílios Ordenados pela Renda Bruta per Capita } \\
\hline & 1 & 2 & 3 & 4 & 5 & 6 & 7 & 8 & 9 & 10 \\
\hline Total & 391 & 737 & 940 & 985 & 1.391 & 1.280 & 1.619 & 2.087 & 3.207 & 8.177 \\
\hline Aposentadoria e Pensão & 113 & 365 & 618 & 727 & 1.152 & 1.090 & 1.421 & 1.923 & 3.035 & 8.054 \\
\hline Seguro-Desemprego & 63 & 75 & 80 & 120 & 69 & 76 & 111 & 89 & 116 & 57 \\
\hline Abono Salarial e Salário-Família & 10 & 65 & 93 & 116 & 74 & 106 & 87 & 76 & 57 & 66 \\
\hline Amparo ao Idoso (Loas) & 24 & 53 & 80 & 17 & 96 & 7 & 0 & 0 & 0 & 0 \\
\hline Programa de Renda Mínima (1) & 182 & 179 & 70 & 4 & 0 & 0 & 0 & 0 & 0 & 0 \\
\hline
\end{tabular}

Fonte: Gasto Social do Governo Central, Ministério da Fazenda, 2003.

(1) Inclui bolsa-escola, bolsa-alimentação e bolsa-criança cidadã. Os benefícios desses programas foram estimados com base na cobertura de 2002 , com valores deflacionados para 1999.

primária $52,6 \%$ dos alunos estão entre os $40 \%$ mais pobres da população, enquanto os $40 \%$ mais ricos correspondem a $24,1 \%$ dos alunos deste nível de ensino. À medida que os níveis educacionais avançam, a porcentagem de acesso dos $40 \%$ mais pobres se reduz, enquanto a dos $40 \%$ mais ricos aumenta. No nível superior, $93,2 \%$ dos estudantes provêm de famílias que estão entre os $40 \%$ mais ricos da população.

Supondo que os estudantes cujas famílias estão entre as $40 \%$ mais pobres da distribuição de consumo do país não têm recursos para pagar ensino particular, os dados da Tabela 3 mostram uma situação particularmente preocupante. Entre os $20 \%$ mais pobres, apenas $28,5 \%$ dos estudantes atingem o ensino médio e é praticamente nula a porcentagem daqueles que chegam ao ensino superior. Já entre os 20\% seguintes, 45,4\% alcançam o ensino médio. Em outras palavras, do total das crianças das famílias que estão entre as $40 \%$ mais pobres do país, apenas $37 \%$ chegam ao ensino médio e, na melhor das hipóteses, 63\% completam o nível primário de educação. Assim, seja por falta de recursos, seja por falta de conhecimento decorrente da qualidade do ensino público fundamental e médio, os $40 \%$ mais pobres não conseguem ingressar na universidade.

A Tabela 4 mostra quem se apropria dos gastos do governo com educação, por faixa de renda. Do total de recursos destinados ao ensino fundamental, 42,7\% são detidos pelos $40 \%$ mais pobres da população, enquanto $35,2 \%$ são apropriados pelos $40 \%$ mais ricos, o que mostra um pequeno grau de progressividade neste tipo de gasto público. Por outro lado, do total de recursos direcionados ao ensino médio, apenas $27,9 \%$ beneficiam os $40 \%$ mais pobres, enquanto $43,4 \%$ são apropriados pe$\operatorname{los} 40 \%$ mais ricos. Finalmente, $90,6 \%$ dos gastos com educação superior são detidos pelos $40 \%$ mais ricos da população.

TABELA 3

Distribuição de Estudantes, por Nível de Educação Pública, segundo Quintil de Consumo Brasil - 1996/97

Em porcentagem

\begin{tabular}{|c|c|c|c|}
\hline Quintil & Primária & Secundária & Nível Superior \\
\hline Total & 100,0 & 100,0 & 100,0 \\
\hline Primeiro Quintil & 26,0 & 7,4 & 0,0 \\
\hline Segundo Quintil & 26,6 & 12,1 & 0,0 \\
\hline Terceiro Quintil & 19,5 & 28,0 & 6,9 \\
\hline Quarto Quintil & 16,5 & 33,3 & 20,3 \\
\hline Quinto Quintil & 7,6 & 19,2 & 72,9 \\
\hline
\end{tabular}

Fonte: von Amsberg; Lanjouw; Nead (2000). 
TABELA 4

Distribuição dos Gastos do Governo em Programas Educacionais, por Faixa de Renda, segundo Nível de Ensino Brasil - 1996

\begin{tabular}{|c|c|c|c|c|c|}
\hline \multicolumn{6}{|c|}{ Em porcentagem } \\
\hline Nível de Ensino & $1^{\circ}$ Quintil & $2^{\circ}$ Quintil & $3^{\circ}$ Quintil & $4^{\circ}$ Quintil & $5^{\circ}$ Quintil \\
\hline Creche & 26,3 & 35,8 & 16,3 & 8,2 & 13,4 \\
\hline Pré-escola & 34,6 & 12,0 & 16,8 & 11,5 & 25,1 \\
\hline Ensino Fundamental & 20,7 & 22,0 & 22,1 & 20,8 & 14,4 \\
\hline Ensino Médio & 8,5 & 19,4 & 28,7 & 29,9 & 13,5 \\
\hline Educação Superior & 0,7 & 1,7 & 7,0 & 45,9 & 44,7 \\
\hline
\end{tabular}

Fonte: Barros; Foguel (2000).

A Tabela 5 mostra a distribuição de pacientes por diferentes tipos de instalação da rede de saúde, por quintil da distribuição de consumo. Verifica-se que o atendimento aos mais pobres está concentrado nos hospitais e postos de saúde públicos, enquanto os hospitais e clínicas financiadas pelo Sistema Único de Saúde - SUS atendem prioritariamente aos mais ricos.

Em resumo, os dados apresentados nesta seção mostram que mais de 50\% dos recursos destinados às transferências governamentais e dos gastos com programas sociais no Brasil são apropriados pelos $40 \%$ mais ricos da população.

\section{INCENTIVOS, POBREZA E CRESCIMENTO}

A existência de um viés tão fortemente pró-idoso nos gastos sociais brasileiros tem conseqüências de longo pra- zo extremamente importantes para o crescimento do país. O primeiro ponto a ser considerado é o elevado custo tributário deste sistema de aposentadorias, que é financiado por meio de imposto sobre os salários que é dividido em duas partes. A primeira corresponde a 10\% do salário e é diretamente paga pelos trabalhadores e a segunda equivale a $20 \%$ do salário e, supostamente, é paga pelas empresas. Ou seja, o custo do sistema de previdência social é de $30 \%$ da folha de salários do segmento formal do mercado de trabalho brasileiro. É um dos sistemas mais caros do mundo, como proporção dos salários dos trabalhadores da ativa.

Este elevado custo do sistema tem conseqüências extremamente importantes sobre o funcionamento do mercado de trabalho no país. A primeira conseqüência é o grande incentivo à informalidade. Caso o trabalhador seja contratado informalmente, nem ele, nem a empresa pagam

TABELA 5

Distribuição dos Pacientes, por Instalações de Saúde, segundo Quintil de Consumo

Brasil - 1996

\begin{tabular}{|c|c|c|c|c|c|}
\hline & & & & & Em porcentagem \\
\hline Quintil & $\begin{array}{l}\text { Total do } \\
\text { Serviço } \\
\text { Público }\end{array}$ & $\begin{array}{l}\text { Hospitais } \\
\text { Públicos }\end{array}$ & $\begin{array}{c}\text { Hospitais } \\
\text { Financiados } \\
\text { pelo SUS }\end{array}$ & $\begin{array}{l}\text { Postos de } \\
\text { Saúde } \\
\text { Públicos }\end{array}$ & $\begin{array}{c}\text { Clínicas } \\
\text { Financiadas } \\
\text { pelo SUS }\end{array}$ \\
\hline Total & 100,0 & 100,0 & 100,0 & 100,0 & 100,0 \\
\hline 1Q Quintil & 16,3 & 20,1 & 8,3 & 20,2 & 2,1 \\
\hline 2 Quintil & 19,5 & 23,2 & 8,8 & 25,5 & 2,7 \\
\hline 3 Quintil & 22,2 & 24,1 & 9,0 & 28,9 & 10,3 \\
\hline 4 Quintil & 23,2 & 23,0 & 28,6 & 18,2 & 31,7 \\
\hline 5 Quintil & 18,6 & 9,6 & 45,3 & 7,2 & 53,2 \\
\hline
\end{tabular}

Fonte: von Amsberg; Lanjouw; Nead (2000). 
a contribuição previdenciária. Isto significa que esta contribuição pode ser negociada entre eles, aumentando o salário do trabalhador e reduzindo o custo da mão-deobra.

O incentivo à informalidade é reforçado pelo fato de que, segundo a Lei Orgânica da Assistência Social - Loas, desde 1992 todo cidadão brasileiro, ao atingir 67 anos de idade, tem direito a uma pensão correspondente a um salário mínimo, independentemente de ter ou não contribuído para a previdência social ao longo de sua vida ativa, desde que prove que não tem outra fonte de renda. O Estatuto do Idoso, aprovado em 2003, estendeu este benefício para os cônjuges - ou seja, duas pessoas no mesmo domicílio poderão receber o benefício - e reduziu a idade para 65 anos. Portanto, um trabalhador poderá optar entre pagar a contribuição previdenciária de $10 \%$ de seu salário ao mês, ao longo de 35 anos, e receber um benefício cujo valor será igual ao seu próprio salário na ativa, desde que este seja menor ou igual a dez salários mínimos, ou não contribuir e receber uma pensão aos 65 anos de idade de um salário mínimo. Não é difícil entender porque uma parcela extremamente pequena dos trabalhadores por conta própria, que podem optar entre contribuir e não contribuir, paga previdência social no Brasil.

Os dados da PNAD mostram que, entre os trabalhadores por conta própria cuja renda os coloca entre os $40 \%$ mais pobres da população, quase $100 \%$ não contribuem para a previdência social. Dos que estão entre os $20 \%$ seguintes na distribuição, 90\% não contribuem e para os seguintes $20 \%$ a proporção dos que contribuem é de $80 \%$. Para os $20 \%$ mais ricos, cerca de $60 \%$ dos trabalhadores não são contribuintes (Néri, 2002:19).

$\mathrm{O}$ incentivo à informalidade tem duas conseqüências importantes. Primeiro, reduz a produtividade do trabalho e, portanto, o crescimento da economia e o salário real dos trabalhadores. Como o incentivo é maior quanto menor o salário do trabalhador, no longo prazo este sistema de incentivos acaba por gerar uma tendência ao aumento da desigualdade da distribuição da renda. O segundo problema é fiscal. O crescimento da informalidade reduz a base sobre a qual as contribuições incidem, diminuindo a arrecadação e aumentando o déficit do sistema. Esta é uma das principais razões pelas quais o déficit do INSS tem sido crescente desde o início dos anos 90, quando foi criada a Loas. Isto significa que ou se eleva a contribuição sobre os salários e aumenta o incentivo à informalidade, ou se eleva a carga tributária geral para financiar o déficit e reduz-se a competitividade da economia.
Da mesma forma que os gastos com previdência social, no Brasil, estão 6 pontos percentuais do PIB acima da norma internacional para países com uma proporção similar de idosos, nossa carga tributária está 16 pontos percentuais acima da norma internacional para países com renda per capita similar à brasileira. Ou seja, enquanto no Brasil a carga de impostos corresponde a $36 \%$ do PIB, em média, países com renda per capita como a brasileira têm uma carga tributária de $20 \%$ do PIB. Destes $36 \%$ do PIB, um terço corresponde ao total de gastos da previdência social, que continuam a crescer ao longo do tempo.

Além do incentivo à informalidade, o elevado custo da previdência social tem um efeito importante sobre a taxa de poupança privada do país. Concretamente, todos os estudos mostram que, no longo prazo, os impostos sobre os salários acabam sendo pagos pelos próprios trabalhadores, por meio de reduções no salário real, independentemente de quem os recolhe para os cofres do governo, se a empresa ou o trabalhador (Nickell; Bell, 1996). Se isto é verdade, pode-se dizer que os trabalhadores brasileiros recolhem, todos os meses, $30 \%$ de seu salário para financiar o sistema de previdência social. É como se estivessem poupando, forçadamente, $30 \%$ de seu salário para sua aposentadoria.

O problema é que, como o sistema é de repartição, ou seja, as contribuições dos trabalhadores da ativa financiam os gastos com aposentadoria e pensões, esta poupança, em lugar de ser utilizada para financiar investimentos produtivos, que poderiam gerar crescimento do produto e empregos, acaba financiando o consumo de nossos idosos, principalmente daqueles que estão entre os $40 \%$ mais ricos da população. Esta talvez seja uma das razões pelas quais a taxa de poupança voluntária da população brasileira é tão menor do que a dos países do leste asiático, que gastam muito menos com seu sistema de aposentadorias.

Portanto, o alto custo do sistema de previdência social, combinado aos incentivos à informalidade decorrentes da Loas e aos elevados níveis de impostos necessários para manter o equilíbrio fiscal, reduz a taxa de poupança privada, os ganhos de produtividade e, portanto, os salários reais e a taxa de crescimento potencial da economia.

Finalmente, como os gastos com aposentadoria e pensões representam um terço da arrecadação tributária do país, resta muito pouco para ser gasto com outros programas sociais, principalmente com aqueles destinados às crianças, em especial, como visto neste artigo, com educação fundamental. Nestas condições, o Estado não consegue financiar o principal mecanismo de ascensão social 
e econômica das famílias pobres, que é a acumulação de capital humano através de boas escolas públicas.

O resultado é que os filhos das famílias pobres entram no mercado de trabalho em condições de competitividade muito piores do que os filhos das famílias ricas, que estudam em escolas particulares, ou porque completam poucos anos de estudo ou porque suas escolas são de baixa qualidade. Como $50 \%$ das crianças brasileiras vivem em famílias pobres e, destas, $80 \%$ não concluem o ensino fundamental, aproximadamente $40 \%$ dos adultos brasileiros no futuro não terão completado oito anos de estudos. Dificilmente conseguirão trabalho decente, com remuneração adequada. Serão os pobres do futuro, ou seja, criamos um sistema no qual reproduzimos a pobreza de nossa população para financiar o consumo de nossos idosos.

Um programa social que foi proposto exatamente para quebrar este ciclo de reprodução da pobreza, por meio da geração de incentivos corretos, foi o programa bolsa-escola. Este programa foi desenhado com dois objetivos explícitos: reduzir a pobreza no presente; e diminuir o custo de oportunidade para as famílias pobres manterem seus filhos na escola (Camargo, 1991 e 1993; Almeida; Camargo, 1994).

A idéia original do programa bolsa-escola, assim como de todos aqueles de transferência de renda condicionada, era transferir renda para todas as famílias desde que matriculassem todos os seus filhos em idade escolar em escolas públicas. O principal objetivo do programa seria criar um incentivo para que as crianças fossem matriculadas nas escolas públicas, através da redução do custo de oportunidade de estar na escola. O ponto fundamental é que um dos principais custos para as famílias pobres manterem suas crianças na escola é exatamente a renda que esta criança tem que abrir mão por não estar no mercado de trabalho, ou seja, o custo de oportunidade do tempo gasto na escola. Ao se remunerarem as crianças para que elas estudem, este custo de oportunidade é reduzido, fazendo com que, conseqüentemente, as famílias decidam manter seus filhos na escola e retirá-los do mercado de trabalho. Dois aspectos são importantes nesta proposta.

Primeiro, que a focalização da transferência não se dê pela renda da família. Isto porque, ao focalizar pelo critério de renda, cria-se um incentivo para que as pessoas reportem renda menor do que a efetivamente recebida. Existem métodos sofisticados de superar este problema, mas, como são caros e de difícil implementação, optou-se pela focalização através da freqüência em escolas públicas. Supostamente, a maior parte das crianças que freqüentam escolas públicas vêm de famílias que estão na parte de baixo da distribuição de rendimentos.

O segundo aspecto importante é que todas as crianças em idade escolar deveriam estar freqüentando a escola de tal forma a criar um incentivo adicional para que as novas famílias pobres reduzam o número de filhos.

$\mathrm{Na}$ forma como foi implementado o programa, a renda foi o critério de focalização e o benefício foi dado para cada criança, no máximo até três crianças por família. Ambas as mudanças tendem a tornar os incentivos menos efetivos, mas não os destroem totalmente.

É importante notar que existe uma diferença importante entre os programas de transferência condicionada de renda, como o bolsa-escola e, mais recentemente, o Benefício Social Único (Camargo; Ferreira, 2001) (programa similar ao bolsa-família, implementado pelo governo) e os programas de transferência não condicionada de renda, como a Loas, que é um programa de renda mínima sem condicionalidades. A diferença está exatamente no tipo de incentivo criado pelos dois programas. No primeiro caso, a condicionalidade restringe $o$ acesso ao programa e aumenta os incentivos que se pretende desenvolver, reduzindo, ao mesmo tempo, a possibilidade de comportamento oportunista por parte dos beneficiários do programa, como diminuir a intensidade de procura por emprego enquanto está recebendo seguro-desemprego. No programa de garantia de renda mínima, estes efeitos não se verificam e, como visto no caso da Loas, pode gerar incentivos perversos para o funcionamento da economia.

\section{CONCLUSÕES}

Como tentou-se mostrar neste artigo, os programas sociais brasileiros têm dois vieses que os tornam pouco eficientes no sentido de diminuir a desigualdade da renda e a pobreza no país. O viés pró-idoso e o viés antipobres. Do total de recursos gastos pelo governo federal com programas sociais, $60 \%$ se destinam ao pagamento de aposentadorias e pensões. Isto representa $12 \%$ do PIB do país, o que é o dobro do que a média dos países que têm proporção de idosos na população similar à do Brasil $(5,85 \%)$ gasta com porcentagem de seus respectivos PIB. Por outro lado, $65 \%$ destes recursos são apropriados pelos $40 \%$ mais ricos da população.

No outro extremo, o Estado brasileiro gasta pouco com educação e uma parte substancial desta despesa é apropriada pelos $40 \%$ mais ricos. Concretamente, apenas 3,6\% do PIB do país, em 2000, eram gastos com educação fun- 
damental, enquanto $29,6 \%$ da população brasileira tinha naquele ano entre 0 e 14 anos de idade.

O resultado desta estrutura de gastos sociais criou um mecanismo de reprodução da pobreza ao longo do tempo. Uma parcela substancial das crianças brasileiras vive em famílias pobres (50\%). Destas crianças, mais de $80 \%$ não completam o ensino fundamental, ou seja, não possuem oito anos de estudos, ou porque não têm condições de fazê-lo por precisar entrar no mercado de trabalho muito cedo, ou porque as escolas públicas a que têm acesso são de tão baixa qualidade que são incapazes de mantê-las. Como conseqüência, $40 \%$ das crianças brasileiras, ao se tornarem adultas, terão menos de oito anos de estudos. Dificilmente conseguirão um trabalho decente. Serão os pobres do futuro.

A proposta do programa bolsa-escola tem por objetivo exatamente criar os incentivos corretos para quebrar este círculo de reprodução da pobreza. Entretanto, como um terço das receitas do governo são destinadas ao pagamento de aposentadorias e pensões, sobram poucos recursos para o financiamento de programas como o bolsa-escola. Reduzir os gastos públicos com aposentadorias e pensões, como proporção do PIB, é uma condição essencial para que recursos possam ser redirecionados para melhorar o capital humano das crianças das famílias pobres brasileiras e, com isto, reduzir a pobreza no futuro.

\section{NOTA}

1. The World Bank, Brazil - Municipal education - Resources, Incentives and results apud Schwartzman (2004).

\section{REFERÊNCIAS BIBLIOGRÁFICAS}

ALMEIDA, H.; CAMARGO, J.M. Human capital investment and poverty. PUC-Rio, Departamento de Economia, 1994. (Texto para discussão, n. 319).

BANCO MUNDIAL. Attacking Brazil's Poverty, White Cover Draft Report n.20.475-BR, Washington, v.I, June 2000.

BARROS, R.P.; FOGUEL, M. Focalização dos gastos públicos sociais e erradicação da pobreza no Brasil. In: HENRIQUES, R. (Org.). Desigualdade e pobreza no Brasil. Rio de Janeiro: Ipea, 2000 .

BARROS, R.P.; HENRIQUES, R.; MENDONÇA, R. A estabilidade inaceitável: desigualdade e pobreza no Brasil. In: HENRIQUES,
R. (Org.). Desigualdade e pobreza no Brasil. Rio de Janeiro: Ipea, 2000a.

Education and equitable economic development, Economia, v.1, n.1, jan. 2000b.

BRANDT, R. Desenvolvimento social, previdência e pobreza no Brasil. Conjuntura Social, v.12, n.2, abr./jun. 2001.

CAMARGO, J.M. Os miseráveis. Folha de S.Paulo, São Paulo, 27 mar. 1993.

Pobreza e garantia de renda mínima. Folha de S.Paulo, São Paulo, 26 dez. 1991.

CAMARGO, J.M.; FERREIRA, F.H.G. Missing the target; assessing social expenditures in Brazil. The Brown Journal of World Affairs, v.VIII, n.2, winter 2002.

O beneficio social único: uma proposta de reforma da política social no Brasil. PUC-Rio, Departamento de Economia, 2001. (Texto para discussão, n.443).

The poverty reduction strategy of the government of Brazil: a rapid appraisal. PUC-Rio, Departamento de Economia, 2000. (Texto para Discussão, n.417).

GIAMBIAGI, F.; REIS, J.G.; URANI, A. (Orgs.). Reformas no Brasil: balanço e agenda. [S.1.]: Nova Fronteira, 2004.

HOFFMAN, R. Aposentadorias e pensões e a desigualdade da distribuição da renda no Brasil. Econômica, v.5, n.1, jun. 2003.

LOPES, F.M. Avaliação de programas de transferência direta de renda: o caso do Programa de Garantia de Renda Familiar Mínima do município de Campinas. Dissertação (Mestrado) Departamento de Economia da Universidade Estadual de Campinas, Campinas, dez. 1999.

MINISTÉRIO DA FAZENDA. Gasto social do governo central: 2001, 2002. Brasília: Secretaria de Política Econômica, 2003.

NÉRI, M. Reforma previdenciária: em busca de incentivos para atrair o trabalhador autônomo. Ensaios Econômicos, EPGE/FGV, n.460, 2002 .

NICKELL, S.J.; BELL, B. Would cutting pauroll taxes on the unskilled have a significant impact on unemployment? In: SNOWER, D.J.; DEHESA, G. de la. Unemployment policy: government options for the labor market. Center for Economic Policy Research, 1996.

PINHEIRO, V.C. Reforma da previdência: uma perspectiva comparada. In: GIAMBIAGI, F.; REIS, J.G.; URANI, A. (Orgs.). Reformas no Brasil: balanço e agenda. [S.1.]: Nova Fronteira, 2004.

SCHWARTZMAN, S. Educação: a nova geração de reformas. In: GIAMBIAGI, F.; REIS, J.G.; URANI, A. (Orgs.). Reformas no Brasil: balanço e agenda. [S.1.]: Nova Fronteira, 2004.

SEN, A. Poor, relatively speaking. Oxford Economic Papers, n.35, p.153-69, 1983.

VON AMSBERG, J.; LANJOUW, P.; NEAD, K. A focalização do gasto social sobre a pobreza no Brasil. In: HENRIQUES, R. (Org.). Desigualdade e pobreza no Brasil. Rio de Janeiro: Ipea, 2000 .

José Márcio Camargo: Professor do Departamento de Economia da PUC-Rio. 